\title{
Pulmonary regurgitation and pulmonary branch kinking: long-term complication in adults with repaired tetrallogy of Fallot
}

\author{
Blanka Glavaš Konja*, Maja Strozzi, Darko Anić, Sandra Večerić, Sanja Ceković, \\ Jadranka Šeparović Hanževački \\ University Hospital Center Zagreb, Zagreb, Croatia
}

The major long-term complication of tetralogy of Fallot repair is pulmonary valve insufficiency, which leads to right heart failure ${ }^{1-3}$. Other problems include atrial and ventricular arrhythmias and sudden cardiac death ${ }^{4}$.

We report a case of progressive pulmonary valve regurgitation late after tetralogy of Fallot correction. A 26-year old woman with history of Ductus Botalli closure and complete tetralogy of Fallot correction at the age of two, was evaluated for palpitation, intermittent leg edema, progressive exertion intolerance New York Heart Association (NYHA) functional class II/III and a syncope episode. On examination, sinus rhythm and a systolic and early diastolic murmur was noted at the high left sternal border and at the back. Electrocardiography shows right ventricular (RV) hypertrophy with a right bundle branch block. First transthoracic echocardiogram (TTE) showed right ventricle hypertrophy (Figure 1) and mild pulmonary valve regurgitation. The presence of Doppler flow turbulence and increased velocity jet in the left branch pulmonary artery was suggesting the stenosis. Magnetic resonance imaging (MRI) also showed right ventricular hypertrophy, mild pulmonary regurgitation and narrowing of the main pulmonary artery at branching (diameter $12 \mathrm{~mm} / 20$ $\mathrm{mm}$ ) suggesting mild stenosis. Cardiac catheterization con- firmed the diagnosis of anomal coronary artery origin, all from the right coronary sinus. Left pulmonary artery stenosis with pressure gradient less than $20 \mathrm{mmHg}$ was detected on right pulmonary angiography. A computed tomographic scan of thorax was further arranged to delineate the pulmonary artery anatomy; this confirmed mild left branch pulmonary artery narrowing. Perfusion lung scan ratio was $65 \%$ right to $35 \%$ left. In 6 months follow-up, progressive dyspnea and exercise intolerance occurred. Control TTE revealed significant impairment of pulmonary regurgitation (Figure 2). Stress TTE confirmed increase in pulmonary regurgitation while significant pulmonary transvalvular and peripheral pulmonary gradient remained the same. Patient was scheduled for surgery. At operation, the main left pulmonary artery was found to be kinked with adhesions. The annulus of the pulmonary valve was dilated and one of the cusps was completely destructed. Left pulmonary artery unkinking and pulmonary bioprosthetic valve replacement was done. Soon after operation the patient made an uneventful recovery.

At her 6-month follow-up, she remains in NYHA functional class I with no symptoms, follow-up TTE revealed reversal remodeling of the $\mathrm{RV}$, normal bioprosthetic function, transpulmonary and peripheral flow.

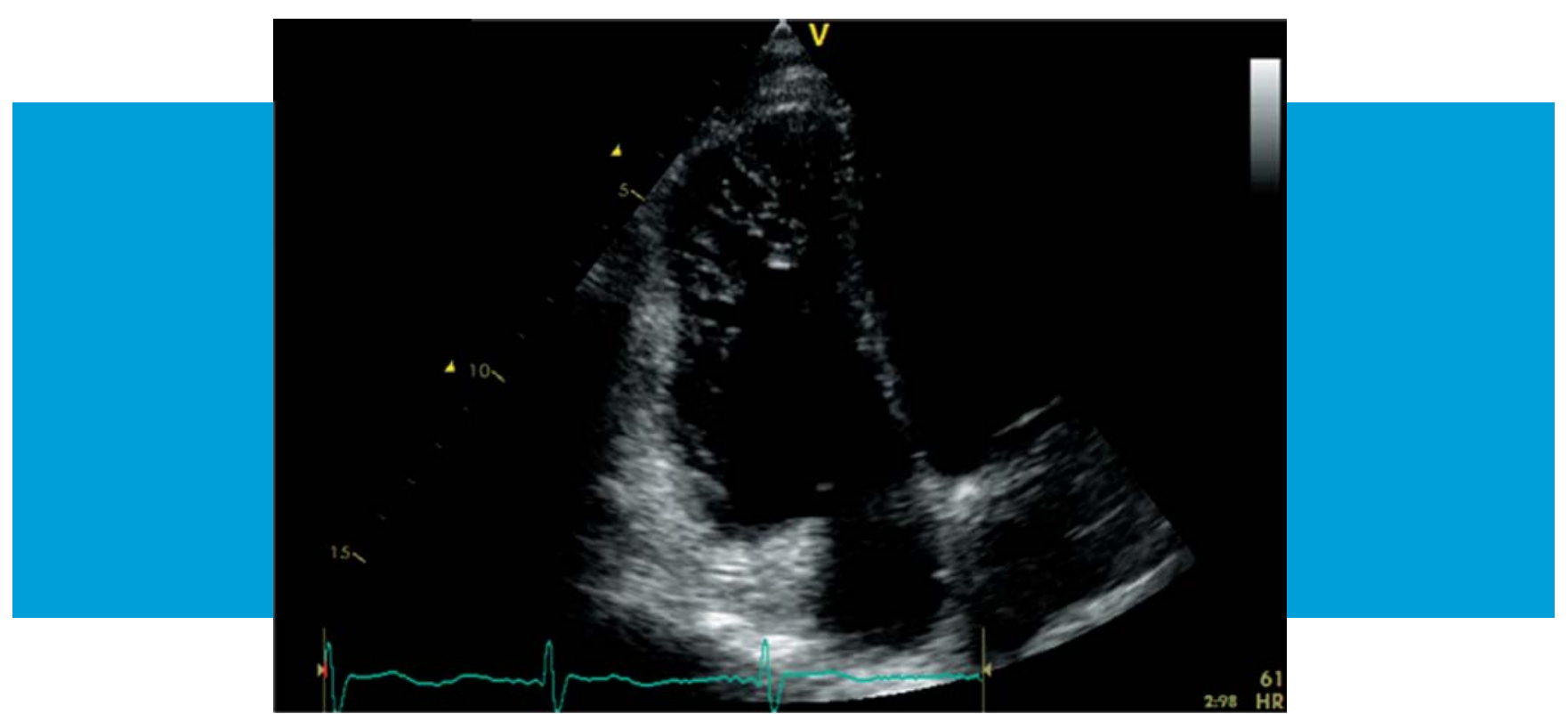

Figure 1. Transthoracic apical view demonstrates severe right ventricular hypertrophy. 


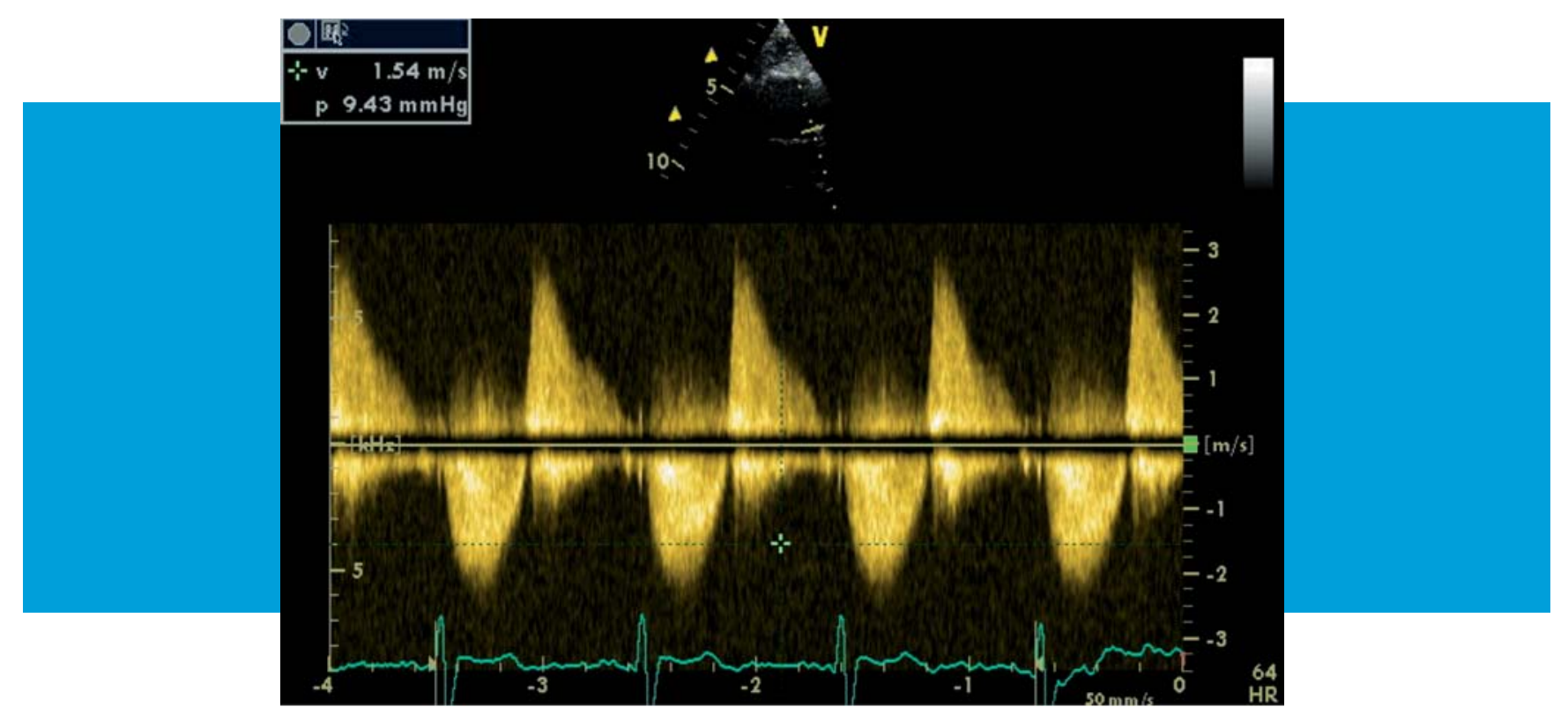

Figure 2. Steep deceleration and intense signal of pulmonary regurgitation jet on control transthoracic echocardiogram.

KEYWORDS: tetralogy of Fallot, pulmonary regurgitation, pulmonary branch stenosis, echocardiography.
Received: $20^{\text {th }}$ Mar 2013

*Address for correspondence: Klinički bolnički centar Zagreb, Kišpatićeva 12, HR-10000 Zagreb, Croatia.

Phone: +385-1-2388-888

Email: blanka.glavas@gmail.com

\section{Literature}

1. Cheung MM, Konstantinov IE, Redington AN. Late complications of repair of tetralogy of Fallot and indications for pulmonary valve replacement. Semin Thorac Cardiovasc Surg. 2007;17:155-9.

2. Ammash NM, Dearani JA, Burkhart HM, Connolly HM. Pulmonary regurgitation after tetralogy of Fallot repair: clinical features, sequelae, and timing of pulmonary valve replacement. Congenit Heart Dis. 2007;2:386-403.

3. Geva T. Repaired tetralogy of Fallot: the roles of cardiovascular magnetic resonance in evaluating pathophysiology and for pulmonary valve replacement decision support. $J$ Cardiovasc Magn Reson. 2011;13:9.

4. Gatzoulis MA, Balaji S, Webber SA, et al. Risk factors for arrhythmia and sudden cardiac death late after repair of tetralogy of Fallot: a multicentre study. Lancet. 2000;356:97581. 